\title{
Non-optimal effectiveness of convalescent plasma transfusion and hydroxychloroquine in treating COVID-19: a case report
}

\author{
Tian-min Xu' ${ }^{1}$ Bin Lin², Cong Chen ${ }^{3}$, Long-gen Liu and Yuan Xue ${ }^{4^{*}}$ (D)
}

\begin{abstract}
Background: Convalescent plasma (CP) transfusion was reported to be effective in treating critically ill patients with COVID-19, and hydroxychloroquine could potently inhibit SARS-CoV-2 in vitro. Herein, we reported a case receiving combination therapy with CP transfusion and hydroxychloroquine for the first time.

Case presentation: Laboratory findings showed high lactic acid level $(2.1 \mathrm{mmol} / \mathrm{L})$ and $C$-reactive protein (CRP, $48.8 \mathrm{mg} / \mathrm{L})$, and low white blood cell count $\left(1.96 \times 10^{9} / \mathrm{L}\right)$ in a 65 -year-old Chinese man, who was diagnosed with severe COVID-19. CP was intravenously given twice, and hydroxychloroquine was orally administrated for a week $(0.2 \mathrm{~g}$, three times a day). The lactic acid and C-reactive protein levels remained high $(2.1 \mathrm{mmol} / \mathrm{L}$ and $73.23 \mathrm{mg} / \mathrm{L}$, respectively), while the arterial oxyhemoglobin saturation decreased to $86 \%$ with a low oxygenation index (OI, 76 $\mathrm{mmHg}$ ) on day 4 after $\mathrm{CP}$ transfusion. His temperature returned to normal and the Ol ascended above 300 on day 11. Moreover, the RNA test remained positive in throat swab, and computed tomography revealed severe pulmonary lesions on day 11 after admission.
\end{abstract}

Conclusion: These findings suggested that the effectiveness of combination therapy with CP and hydroxychloroquine may be non-optimal, and specific therapy needs to be explored.

Keywords: COVID-19, SARS-CoV-2, Convalescent plasma, Hydroxychloroquine, Cycle threshold

\section{Background}

Coronavirus disease 2019 (COVID-19), caused by severe acute respiratory syndrome coronavirus 2 (SARS-CoV2 ), is a pandemic that is rapidly spreading worldwide. It has been reported that $10-20 \%$ of severe patients with mild atypical symptoms initially, can rapidly progress to acute respiratory distress syndrome, the main cause of respiratory failure [1].

Few studies have reported the effectiveness of convalescent plasma $(\mathrm{CP})$ transfusion in treating critically ill patients with COVID-19 [2-4]. The clinical symptoms were significantly improved within 3 days, and the viral

\footnotetext{
*Correspondence: xueyuan80908@163.com

${ }^{4}$ Institute of Hepatology, the Third People's Hospital of Changzhou, No. 300 Lanling North Road, Changzhou 213000, Jiangsu, China

Full list of author information is available at the end of the article
}

load was undetectable within 7 days after CP transfusion [3]. These results are encouraging and worthy of further investigation. Nevertheless, Zeng et al. [5] reported that SARS-CoV-2 became undetectable after CP transfusion, but it could not reduce mortality in critically ill COVID19 patients.

Moreover, hydroxychloroquine was found to be active against SARS-CoV-2 in vitro, and is a treatment option in clinical practice. Yao et al. [6] reported that hydroxychloroquine was more potent than chloroquine to inhibit SARS-CoV-2 in vitro.

Herein, we administered CP transfusion and hydroxychloroquine to a patient with severe COVID-19, and analyzed their clinical symptoms, oxygenation index (OI), and dynamics of viral load. 

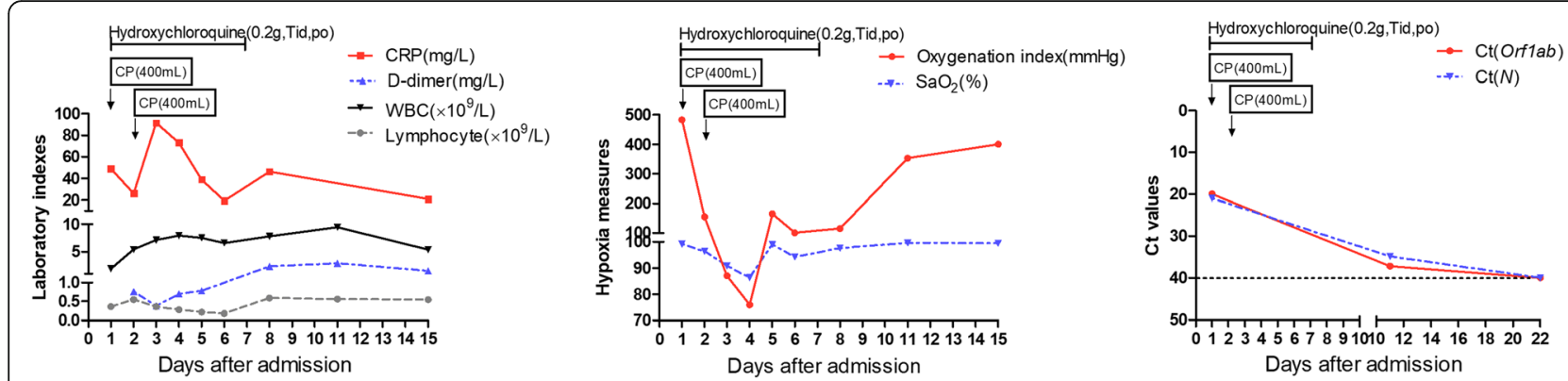

Fig. 1 Dynamics of laboratory indexes in the patient with severe COVID-19 receiving convalescent plasma and hydroxychloroquine treatment. CP, convalescent plasma; CRP, C-reactive protein; WBC, white blood cells; SaO2, oxyhemoglobin saturation; Ct, cycle threshold

\section{Case presentation}

A 65-year-old Chinese man, who was diagnosed with laboratory-confirmed COVID-19, was admitted to our isolation ward on 25 March 2020. A week before his admission, he flew in from Brazil airport, and was subsequently under home isolation. On 23 March 2020, he presented with fever $\left(38.8^{\circ} \mathrm{C}\right)$, chills and myalgia. Viral RNA test from throat swab was positive. The cycle threshold $(\mathrm{Ct})$ values of open reading frame 1ab (Orflab) and nucleocapsid $(N)$ genes by RT-PCR assay were 20 and 21, indicating a high viral load. Computed tomography (CT) scan showed bilateral pneumonia. Laboratory findings showed high lactic acid level $(2.1 \mathrm{mmol} / \mathrm{L})$ and C-reactive protein $(\mathrm{CRP}, 48.8 \mathrm{mg} / \mathrm{L})$, and low white blood cell count $\left(1.96 \times 10^{9} / \mathrm{L}\right)$, indicative of severe COVID-19. Oxygen and atomized inhalation of recombinant human interferon-a2b was given at admission. $\mathrm{CP}$ from two convalescent patients was intravenously given, and hydroxychloroquine (Shanghai Zhongxi Pharmaceuticals, Shanghai, China) was orally administrated for a week ( $0.2 \mathrm{~g}$, three times a day).
As shown in Fig. 1, on day 4 after $\mathrm{CP}$ transfusion, the lactic acid and CRP levels remained high $(2.1 \mathrm{mmol} / \mathrm{L}$ and $73.23 \mathrm{mg} / \mathrm{L}$, respectively). The arterial oxyhemoglobin saturation $\left(\mathrm{SaO}_{2}\right)$ decreased to $86 \%$, while the OI decreased to $76 \mathrm{mmHg}$, and mechanical ventilation was administered. His temperature returned to normal and the OI ascended above 300 on day 11, after which the ventilator was withdrawn. On day 11 after $\mathrm{CP}$ transfusion, the RNA test remained positive in throat swab, and $\mathrm{CT}$ revealed severe pulmonary lesions (Fig. 2).

In addition, no apparent side-effects were found during $\mathrm{CP}$ transfusion and hydroxychloroquine treatments.

\section{Discussion and conclusion}

Currently, the pathogenesis of COVID-19 remains unclear, and no specific treatment is available. Cytokine storm and excessive inflammation coexist and may lead to multiple organ failure. Both antiviral therapy and treatment of the systematic response are important for patients with rapid deterioration of COVID-19.

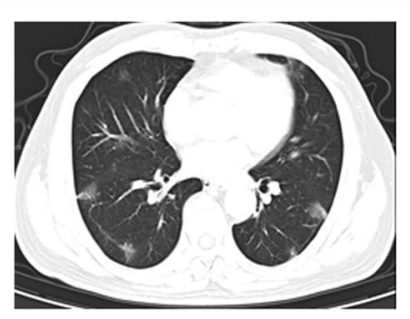

Day 1

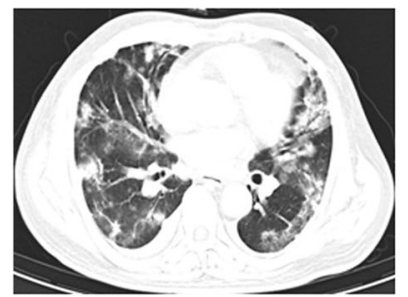

Day 11

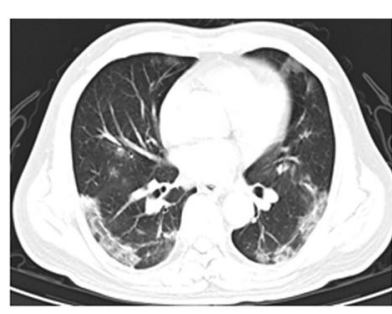

Day 3

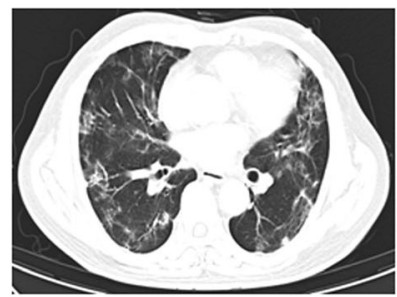

Day 18

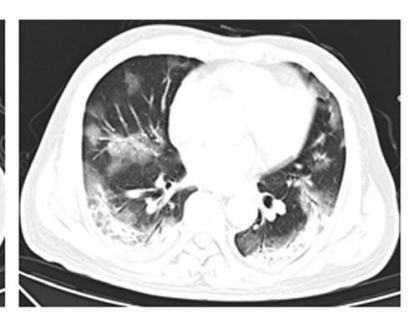

Day 4

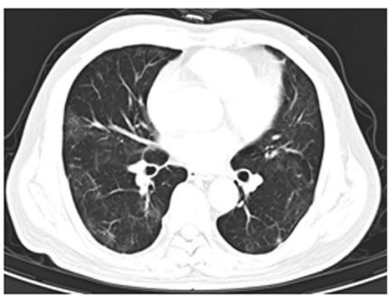

Day 32

Fig. 2 Dynamics of computed tomography scans after admission 
In a study with small sample size, the median time from onset of illness to $\mathrm{CP}$ transfusion was 16.5 days, and the disappearance of viremia was observed in 7 days after CP transfusion [3]. The results suggested that CP therapy could potentially improve the clinical outcomes by neutralizing viremia in severe COVID-19 [3]. In another study, CP transfusion was given at a median of 21.5 days after first detection of SARS-CoV-2, the viral load became negative 3 days after $\mathrm{CP}$ transfusion, though 5 of 6 patients died eventually [5]. Unexpectedly, the viral load remained detectable on day 11 after combination therapy with $\mathrm{CP}$ and hydroxychloroquine. Considering the time from onset of illness to $\mathrm{CP}$ transfusion in previous studied $[3,5]$, it is difficult to prove whether the viremia is cured by the CP and antiviral agent, or is a natural course of COVID-19. Indeed, there is a limitation that antibodies against SARS-CoV-2 in CP from the two convalescent patients and the present patient are not detected. Based on our clinical experience, sufficient evidence supporting the use of $\mathrm{CP}$ and hydroxychloroquine in treating COVID-19 is lacking.

Our findings suggested that the effectiveness of combination therapy with $\mathrm{CP}$ and hydroxychloroquine may be non-optimal, and specific therapy needs to be explored.

\section{Abbreviations}

CP: Convalescent plasma; COVID-19: Coronavirus disease 2019; SARS-CoV2: Severe acute respiratory syndrome coronavirus 2; Ol: Oxygenation index; Ct: Cycle threshold; Orfiab: Open reading frame 1ab; CT: Computed tomography; CRP: C-reactive protein

\section{Acknowledgements}

Not applicable.

\section{Authors' contributions}

Tian-min Xu, Bin Lin, Cong Chen, Long-gen Liu, Yuan Xue collected and confirmed the data. Yuan Xue, Tianmin Xu and Bin Lin performed the analysis and drafted the manuscript. All authors read and approved the final manuscript. Tianmin Xu and Bin Lin contributed equally to this work.

\section{Funding}

This work was supported by the Natural Science Foundation of Jiangsu Province (Grant No. BK20180183), and the Science and Technology Project of Jintan (Grant No. KJ201925).

\section{Availability of data and materials}

Derived data are available on reasonable request.

\section{Ethics approval and consent to participate}

This study was approved by the Ethics Committee of the Third People's Hospital of Changzhou, and was performed in accordance with the 1975 Declaration of Helsinki.

\section{Consent for publication}

Written consent was obtained from the patient for publication.

\section{Competing interests}

All authors declare no conflict of interest.

\section{Author details}

'Department of Infectious Diseases, the Third People's Hospital of Changzhou, Changzhou, Jiangsu, China. ${ }^{2}$ Department of Infectious Diseases, the First People's Hospital of Jintan, Changzhou, Jiangsu, China. ${ }^{3}$ Changzhou Center for Disease Control and Prevention, Changzhou, Jiangsu, China. ${ }^{4}$ Institute of Hepatology, the Third People's Hospital of Changzhou, No. 300 Lanling North Road, Changzhou 213000, Jiangsu, China.

Received: 6 May 2020 Accepted: 12 June 2020

Published online: 19 June 2020

\section{References}

1. Chen N, Zhou M, Dong X, Qu J, Gong F, Han Y, et al. Epidemiological and clinical characteristics of 99 cases of 2019 novel coronavirus pneumonia in Wuhan, China: a descriptive study. Lancet. 2020;395(10223):507-13.

2. Shen C, Wang Z, Zhao F, Yang Y, Li J, Yuan J, et al. Treatment of 5 critically III patients with COVID-19 with convalescent plasma. JAMA. 2020;323(16): 1582.

3. Duan K, Liu B, Li C, Zhang H, Yu T, Qu J, et al. Effectiveness of convalescent plasma therapy in severe COVID-19 patients. Proc Natl Acad Sci U S A. 2020; 117(17):9490-6.

4. Zhang B, Liu S, Tan T, Huang W, Dong Y, Chen L, et al. Treatment with convalescent plasma for critically ill patients with severe acute respiratory syndrome coronavirus 2 infection. Chest. 2020. https://doi.org/10.1016/j. chest.2020.03.039.

5. Zeng QL, Yu ZJ, Gou JJ, Li GM, Ma SH, Zhang GF, et al. Effect of convalescent plasma therapy on viral shedding and survival in COVID-19 patients. J Infect Dis. 2020. https://doi.org/10.1093/infdis/jiaa228.

6. Yao X, Ye F, Zhang M, Cui C, Huang B, Niu P, et al. In vitro antiviral activity and projection of optimized dosing design of Hydroxychloroquine for the treatment of severe acute respiratory syndrome coronavirus 2 (SARS-CoV-2). Clin Infect Dis. 2020. https://doi.org/10.1093/cid/ciaa237.

\section{Publisher's Note}

Springer Nature remains neutral with regard to jurisdictional claims in published maps and institutional affiliations.
Ready to submit your research? Choose BMC and benefit from:
- fast, convenient online submission
- thorough peer review by experienced researchers in your field
- rapid publication on acceptance
- support for research data, including large and complex data types
- gold Open Access which fosters wider collaboration and increased citations
- maximum visibility for your research: over $100 \mathrm{M}$ website views per year
At BMC, research is always in progress.
Learn more biomedcentral.com/submissions 